\title{
APPLICATION OF LARGE-SCALE PHOTOGRAPHY TO A FOREST INVENTORY ${ }^{1}$
}

\section{A. H. ALDRED ${ }^{2}$ and J. K. HALL ${ }^{3}$}

\section{Abstract}

For many years the Forest Management Institute has been developing a large-scale photography system for forest inventory. The role of this system is to replace most, but not all, of the ground work required to make sample plot estimates of species composition, measurements of tree variables such as height, diameter and volume and stand estimates such as stocking, basal area, volume and the distribution of trees by diameter and volume classes.

The development of the method, until recently, concentrated mainly on overcoming technical problems limiting the accuracy of the tree measurements and the reliability of the species identification. Significant progress on such problems had led to a shift in emphasis to cost-efficiency considerations and the practical problems of implementing the method. This paper outlines the problems encountered in recent operational trials of the method, provides some results on production costs and indicates plans to overcome some of the remaining problems.

\section{Résumé}

Depuis plusieurs années, I'Institut d'aménagement forestier s'emploie à développer un système photographique à grande échelle pour faire I'nventaire forestier. Ce système a pour but de remplacer en grande partie, mais pas complètement, le travail sur le terrain nécessaire pour évaluer, sur des parcelles d'échantillonnage, la composition par espèces, mesurer des variables telles la hauteur, le diamètre et le volume des arbres et réaliser, pour ce qui est des peuplements, des estimations concernant par exemple le reboisement, la surface terrière, le volume et la distribution des arbres en fonction des classes de volume et de diamètre.

Jusqu'à récemment, le développement de la méthode a surtout porté sur l'élimination des problèmes techniques timitant la precision du mesurage

\footnotetext{
1Paper presented under the title "Practical problems of applying large-scale photography to forest inventory", at Can. Inst. For. Meet., Oct. 1973 in Prince Albert, Sask.

${ }^{2}$ Chief, Forest Appraisal Program, Forest Management Institute, Canadian Forestry Service, Department of the Environment, Ottawa, Ontario, K1A OW2,

3Previously with Forest Appraisal Program, Forest Management Institute, Canadian Forestry Service, Ottawa, Ontario. Now Civil Engineer, with the Operational Research Branch, City of Vancouver Engineering Department, Vancouver, B.C.
}

des arbres et l'exactitude de l'identification des espèces. Des progrès significatifs ayant été effectués dans ce domain, on s'est alors concentré sur des considérations de coûts/efficacité et sur les problèmes pratiques de l'implantation de la méthode. La présente communication donne un aperçu des problèmes rencontrés lors de récents essais opérationnels et fourni tdes indications sur les coûts de production et sur la façon de résoudre quelquesuns des problèmes auxquels on n'a pas encore trouvé de réponse.

\section{References}

Aldred, A. H. and L. Sayn-Wittgenstein. 1972. Tree diameters and volumes from large-scale aerial photographs. Dep. Environ., Can. For Serv., Forest Manage. Inst., Inf. Rep. FMR-X-40, $39 \mathrm{p}$.

Bonnor, G. M. 1974. A forest sampling design for inventories using largescale aerial photography. Univ. Microfilms, Ann Arbor, Mich., Diss. Abstr. Int. 34(10).

Brun, R. 1972. A new stereotopedigitizer system for measuring and processing tree data from largescale aerial photographs. Can. For. Serv., Dep. Environ., Forest Manage. Inst., Inf. Rep. FMR-X-41, 35 p.

Nielsen, U. 1974a. Description and performance of the forestry radar altimeter. Dep. Environ., Can. For. Serv., Forest Manage. Inst., Inf. Rep. FMR-X-59, 17+vii p.

Nielsen, U. 1974a. Description and pertilt indicator. $\mathrm{XL}(8)$ : 953-956.

Rowe, J. S. 1972. Forest regions of Canada. Dep. Environ., Can. For. Serv., Publ. No. 1300, 172 p.

Sayn-Wittgenstein, L. and A. H. Aldred. 1969. A forest inventory by largescale aerial photography. Pulp and Pap. Mag. Can. 70(17): 92-95.

\section{Introduction}

The major cost components of a forest inventory derive mainly from the expense and difficulty of establishing and measuring sample plots on the ground and from data compilation and tabulation. The high cost of ground work is particularly acute for inventories in remotely located areas and areas where rough topography hampers access. In response to this problem, the Forest Management Institute has been attempting to develop an inventory method based on tree measurements on largescale aerial photographs - an inventory method which would eliminate most of the ground work.

During the early stages of the research work, the main efforts concentrated on developing the airborne system for taking good quality, geometrically stable photographs at low altitude. The rapid development of small-format reconnaissance cameras in the early 60 's contributed greatly to the success. Attention then shifted to the development of techniques for reliably identifying tree species, to assessing the condition of trees and to accurately measuring variables such as tree height, crown size and expression of density or competition between closely associated trees. Regression models then had to be developed which could use these variables to estimate diameter and volume which, in turn, could be used to compile the required inventory statistics.

Until recently, the main concerns were the reliability of the species identification and other qualitative assessments, and the accuracy of the measurements and estimates. Significant progress on these problems was made and a test of the large-scale photo system was conducted in the Mackenzie Valley in 1966 by Sayn-Wittgenstein and Aldred (1969). An operational trial was conducted jointly with the Canadian International Paper Company in 1973. The emphasis of this trial was to demonstrate the methodology while determining the economics of the method and the practical problems of implementation.

This paper sketches the essential features of the method, describes some of the results of the operational trial and points out some of the present limitations and remaining problems. 


\section{Description of the large-scale photo method}

Large-scale photos (scale of 1:500 to about 1:5,000) are taken of selected sample areas; complete photo coverage is not intended. Stereo coverage is obtained of sample plots (Fig. 1) or strips, and trees on the sampling units are numbered, identified and measured following a procedure analogous to ground sampling. A large number of sampling designs can be used including systematic, simple random, stratified random, multiphase, cluster or other multistage designs which endeavour of optimally combine photo and ground sources of data.

The photography is usually done from light, fixed-wing aircraft or small helicopters. The airborne equipment includes one or two aerial cameras, a camera control unit to regulate exposure intervals and aperture settings, a camera mount, a radar altimeter, and a means of controlling or measuring tilt of the camera axis from the vertical during the exposures.

Reconnaissance cameras of $70-\mathrm{mm}$ format are preferred because of their rapid film cycling characteristics (over 10 frames per second) and their fast shutter speeds (down to $1 / 3,000$ of a second). The camera control unit uses an intervalometer to regulate the interval between exposures to ensure the correct stereo overlap.

To determine the scale of the photos, a radar altimeter is used to measure the distance, unaffected by intervening vegetation, from the aircraft to ground (Nielsen 1974). The altitude readings are recorded on the edge of the photos by simultaneously photographing a numerical display in one of two secondary optical systems of the camera (Fig. 1). Photo scale is required for establishing correct sample plot size and tree measurements.

The tilts of the camera axis from the vertical due to aircraft motions can introduce large errors in measurements taken from the assumed vertical photographs. Tilt is controlled by a gyroscopically stabilized camera mount ${ }^{4}$ or measured with a gyro-based instrument (Nielsen
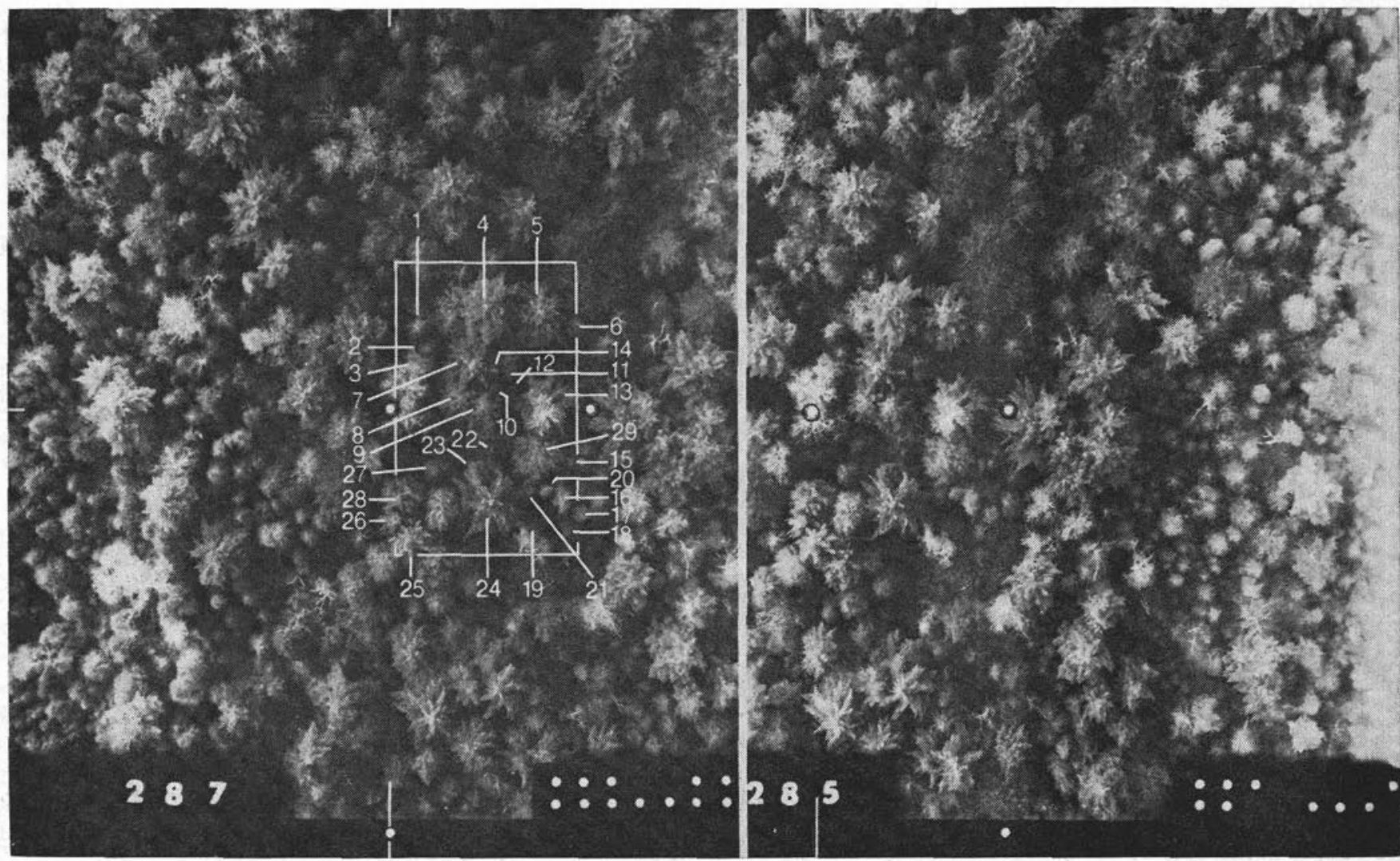

FIG. 1. A stereogram showing a 0.081 -hectare (1/5-acre) large-scale photo plot. Altitude in metres is given in the lower left corner, the tilt data in binary code appears in the lower right corner (FMI photo).

4Hall, J. K. 1974. Operational trial of A-28 stabilized vertical camera mount. Unpublished report.

10 February 1975 The Forestry Chronicle 
1974) with corrections applied during the compilation of measurements. In the latter case, the tilt readings are photographed in the secondary optical system of the camera (Fig. 1).

The lapse time during the photographic mission can be obtained from a digital clock and photographed in the secondary optics of the camera. Time provides some additional photogrammetric information and a useful record of when and where photo strips were stopped and started.

The procedure for measuring the photo plots is as follows. The plot boundary is delineated on the photo according to shape, size and scale specifications. A 0.081 -hectare $(1 / 5$-acre) rectangular plot is illustrated in Fig. 1. All trees larger than a specified size are numbered, identified as to species and measured. Using the photo measurements and the photogrammetric variables (such as altitude and photo-base length), tree height, crown area and expressions of crowding or competition can be determined. These variables are in turn used in regression equations to estimate tree diameter and volume (Aldred and Sayn-Wittgenstein 1972). The tree information collected on the photo plots is set up for machine processing so that the compilation can be carried out automatically. Table 1 shows the tree data for the photo plot in Figure 1 and a plot summary.

A small sub-sample of plots or trees may be ground sampled to check or determine the coefficients of the tree diameter and volume equations and to detect and correct for any systematic errors that may occur in the photo-measurement work.

\section{Recent forest inventory trial}

A forest inventory based on large-scale photography was completed in the spring of 1973. The purpose was to thoroughly test the method, to estab'ish the cost effectiveness of the method and to identify, and attempt to cope with, the practical problems of implementing the method. The work was carried out jointly with the Canadian International Paper Company.

The Inventory Area. A 3,200-acre forest area in western Quebec north of Maniwaki, was used for the trial. The forest is described by Rowe (1972) as belonging to the Great Lakes-St. Lawrence Forest Region (L. 4c). The stands are mainly coniferous: balsam fir, white spruce, red pine, white pine and jack p.ne but small quantities of most northern hardwoods are present. The topography is irregular, varying from nearly flat to rolling terrain.

For the purposes of the inventory trial, only statistics on the con:ferous component were sought: total volume of all conifers and total wood volume for the individual species already mentioned. A simplified, pre-cut cruise best describes this type of inventory.

Sampling Design. A stratified two-stage cluster sampling design was used for the inventory following Bonnor (1974). The design was developed as follows. First the forested area was stratified using 1:20,000 general-coverage ph.otography. In order to simplify the trial, only two strata were used: one based on the predominance of spruce and balsam fir in the main stand canopy, the other based on the predominance of pine. The strata were subsequently divided into strips or clusters, and then subdivided into plots along these strips. Ten strips and about thirty plots were arbitrarily selected for each of two different sampling models: Model 1 based on the selection of strips (clusters) by simple random sampling; Model 2 based on selection of strips with a probability proportional to strip length. In both models, plots were selected within strips by simple random sampling. The configuration of the plots to be sampled by large-scale photography in either design is illustrated in Fig. 2. These designs especially recognized the problem of locating the large-scale photography - by using long strips which cut across easily identified terrain features. Once the strips were positioned, the plots could be readily located within the strips and trees on the plot measured. 
TABLE 1. Tree data for photo plot shown in Figure 1 and plot summary

\begin{tabular}{rlrrrr}
\hline $\begin{array}{l}\text { Tree } \\
\text { number }\end{array}$ & Species & $\begin{array}{c}\text { Crown } \\
\text { area } \\
\left(\mathbf{m}^{2}\right)\end{array}$ & $\begin{array}{c}\text { Height } \\
(\mathbf{m})\end{array}$ & $\begin{array}{c}\text { Diameter } \\
(\mathbf{c m})\end{array}$ & $\begin{array}{c}\text { Total } \\
\text { volume } \\
\left(\mathbf{m}^{3}\right)\end{array}$ \\
\hline $\begin{array}{r}\text { Photo-plot data } \\
\text { 1 }\end{array}$ & & & & \\
2 & bF balsam fir & 5.2 & 9.6 & 12.2 & 0.08 \\
wS white spruce & 3.4 & 8.8 & 9.9 & 0.11 \\
3 & wP white pine & 8.6 & 14.9 & 22.6 & 0.30 \\
4 & wP & 38.9 & 23.2 & 38.4 & 1.32 \\
5 & wP & 41.7 & 18.7 & 34.8 & 0.90 \\
6 & wS & 4.7 & 15.3 & 14.0 & 0.10 \\
7 & wP & 23.3 & 19.2 & 31.0 & 0.73 \\
8 & wP & 15.2 & 17.9 & 27.4 & 0.53 \\
9 & wP & 10.2 & 18.4 & 26.2 & 0.47 \\
10 & wS & 2.2 & 13.6 & 11.5 & 0.08 \\
11 & wS & 2.4 & 11.9 & 10.7 & 0.10 \\
12 & bF & 0.8 & 9.8 & 13.5 & 0.22 \\
13 & wP & 29.7 & 15.1 & 29.2 & 0.47 \\
14 & wS & 1.9 & 14.1 & 10.9 & 0.07 \\
15 & bF & 1.1 & 11.9 & 14.2 & 0.18 \\
16 & jP Jack pine & 5.2 & 16.5 & 14.5 & 0.12 \\
17 & jP & 3.0 & 14.4 & 11.2 & 0.07 \\
18 & jP & 3.8 & 9.4 & 9.1 & 0.12 \\
19 & wS & 6.1 & 13.1 & 13.5 & 0.10 \\
20 & bF & 2.2 & 14.7 & 16.2 & 0.15 \\
21 & bF & 1.8 & 13.7 & 15.5 & 0.15 \\
22 & bF & 2.6 & 9.3 & 12.4 & 0.15 \\
23 & wS & 3.3 & 13.7 & 12.2 & 0.09 \\
24 & wP & 47.9 & 23.5 & 40.4 & 1.50 \\
25 & wP & 14.5 & 21.5 & 30.2 & 0.71 \\
26 & wP & 9.5 & 20.1 & 27.2 & 0.52 \\
27 & wS & 5.6 & 14.9 & 24.2 & 0.11 \\
28 & wS & 23.3 & 16.6 & 24.4 & 0.37 \\
29 & wS & 15.2 & 18.8 & 23.6 & 0.38 \\
& & & & &
\end{tabular}

Plot summary

\begin{tabular}{ccccc}
\hline Species & $\begin{array}{c}\text { No. of } \\
\text { trees }\end{array}$ & $\begin{array}{c}\text { No. of } \\
\text { trees } \\
\text { per hta }\end{array}$ & $\begin{array}{c}\text { Crown } \\
\text { area } \\
\left(\mathbf{m}^{2}\right) \\
\text { per ha }\end{array}$ & $\begin{array}{c}\text { Total } \\
\text { volume } \\
\left(\mathbf{m}^{3}\right) \\
\text { per ha }\end{array}$ \\
\hline wS & 10 & 123 & 841 & 18.5 \\
bF & 6 & 74 & 168 & 11.6 \\
wP & 10 & 123 & 2960 & 92.2 \\
jP & 3 & 37 & 148 & 3.7 \\
TOTAL & 29 & 357 & 4117 & 126.0 \\
\hline
\end{tabular}

TABLE 2. Results of a forest inventory by large-scale photography of an area in Quebec

\begin{tabular}{|c|c|c|c|c|}
\hline Model & Stratum & Species & $\begin{array}{c}\text { Mean } \\
\text { volume }\left(\mathbf{m}^{3}\right) \\
\text { per ha }\end{array}$ & $\underset{\left(\mathbf{m}^{3}\right)}{\begin{array}{c}\text { Total } \\
\text { volume }\end{array}}$ \\
\hline 1 & 1 & 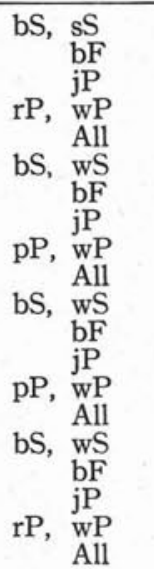 & $\begin{array}{r}9.1 \\
17.5 \\
9.9 \\
7.2 \\
42.3 \\
3.2 \\
10.4 \\
15.6 \\
29.4 \\
47.2 \\
8.2 \\
20.0 \\
4.7 \\
6.9 \\
38.3 \\
9.4 \\
9.4 \\
15.1 \\
21.3 \\
48.9\end{array}$ & $\begin{array}{r}7121 \\
13541 \\
7592 \\
5573 \\
32601 \\
1180 \\
3752 \\
5619 \\
10604 \\
17017 \\
6318 \\
15388 \\
3549 \\
5302 \\
29455 \\
3380 \\
3358 \\
5383 \\
7652 \\
17535\end{array}$ \\
\hline
\end{tabular}

FIG. 3. Photo measurements on digitized Zeiss-stereotope: a) numerical display of $x$ and $y$ coordinates and parallax; (b) card punch; (c) stereotope; (d) key board; (e) foot pedal for data recording. (FMI photo).
TABLE 3. Gost comparison of convention inventory and the method based on large-scale photography

\section{Part A Costs common to both methods}

$\begin{array}{ll}\text { Overhead } & \text { Stratification and mapping } \\ \text { Planning } & \text { Computation } \\ \text { Small-scale photography } & \text { Inventory report }\end{array}$

Small-scale photography Inventory report

Part B Costs NOT common to both methods

\begin{tabular}{|c|c|c|c|c|}
\hline & \multirow[t]{2}{*}{$\begin{array}{c}\text { Conventional } \\
\text { inventory }\end{array}$} & \multicolumn{3}{|c|}{$\begin{array}{l}\text { Large-scale } \\
\text { photo method }\end{array}$} \\
\hline & & $\begin{array}{l}\text { FMI } \\
\text { man } \\
\text { days }\end{array}$ & $\$$ & $\begin{array}{l}\text { \$per } \\
\text { photo } \\
\text { plot }\end{array}$ \\
\hline Equipment depre- & negligible & - & 2000 & - \\
\hline $\begin{array}{l}\text { Large-scale photo- } \\
\text { graphy } \\
\text { Aircraft rental ( } 5 \\
\text { days) }\end{array}$ & - & - & 2400 & - \\
\hline $\begin{array}{l}\text { Equipment instal- } \\
\text { lation and test } \\
\text { flights }\end{array}$ & & & & \\
\hline $\begin{array}{l}\text { flights } \\
\text { Flight personnel }\end{array}$ & 二 & $\begin{array}{l}8 \\
3\end{array}$ & $\begin{array}{l}327 \\
100\end{array}$ & E \\
\hline $\begin{array}{l}\text { Film (3 rolls of } \\
70 \mathrm{~mm})\end{array}$ & - & - & 36 & .57 \\
\hline $\begin{array}{l}\text { Processing and } \\
\text { printing }\end{array}$ & - & 2 & 220 & 3.44 \\
\hline Annotation & 一 & 3 & 142 & 2.25 \\
\hline $\begin{array}{l}\text { Photo measurement } \\
\text { (63 plots) }\end{array}$ & - & 8 & 286 & 4.54 \\
\hline Computer processing & 一 & 2 & 163 & 2.58 \\
\hline $\begin{array}{l}\text { Field measurements } \\
\text { (60 plots) }\end{array}$ & 6000 & 一 & 368 & 一 \\
\hline TOTAL & 6000 & & 6042 & \\
\hline
\end{tabular}

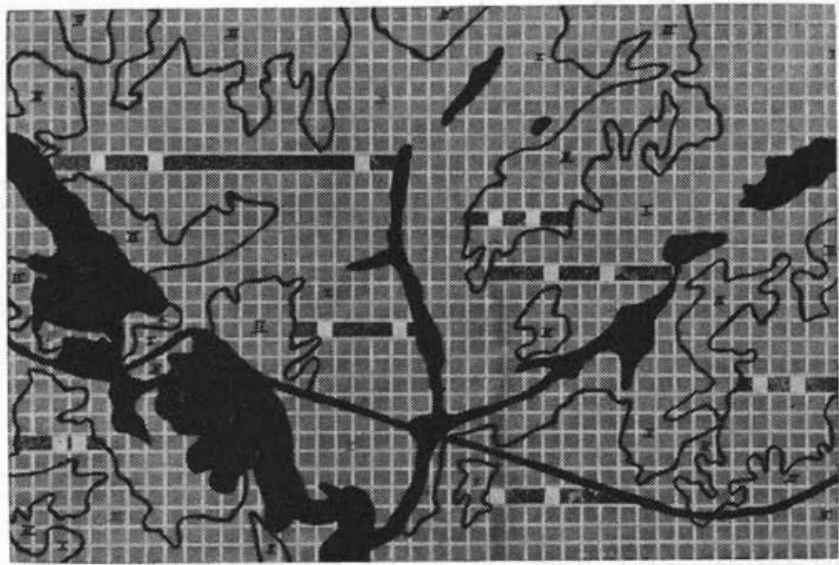

FIG. 2. Sampling design for portion of test area. White squares are plots to be sampled in each black photo strip.

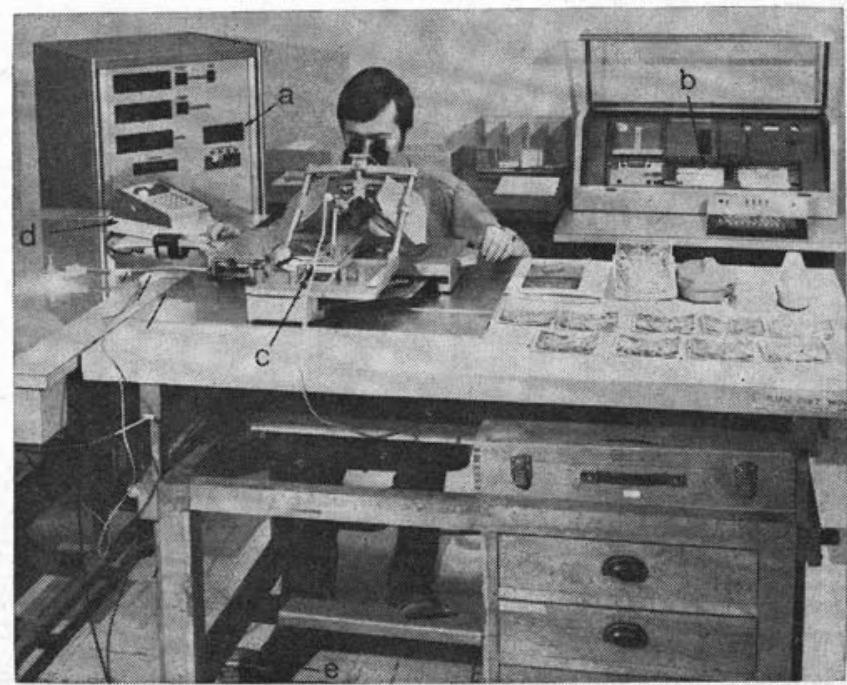


Photo Acquisition. The aerial photography was carried out using Forest Management Institute equipment in a rented aircraft according to the following specifications:

$\begin{array}{ll}\text { Aircraft: } & \text { twin-engine Beechcraft } 18 \\ \text { Camera: } & \text { Vinten 518 - 70 mm } \\ \text { Camera mount: } & \text { gyro-stabilized Aeroflex A-28 } \\ \text { Film: } & \text { panchromatic 400 ASA Agfa Pan } 36 \\ \text { Altimeter: } & \text { G.T.W. Radar Altimeter } \\ \text { Altitude: } & 300 \mathrm{~m} \text { (nominal) } \\ \text { Focal length: } & 153.29 \mathrm{~mm} \\ \text { Stereo overlap: } & 70 \% \text { or more } \\ \text { Photo enlargement: } & 2 \mathrm{X} \\ \text { Time of year: } & \text { early May } \\ \text { Weather conditions: } & \text { clear or under high overcast }\end{array}$

Photo Plot Measurement. As illustrated in Fig. 1, 0.081-hectare (1/5acre) rectangular plots were established by delineating the plot boundary. This plot size, at the design photo scale, provided excellent utilization of the stereo portion of the image format. The photo plot dimensions were adjusted to account for variations in scale.

Trees, estimated to be taller than $10 \mathrm{~m}$, were numbered and identified as to species. Tree variables such as total height and crown area were derived from differential parallax measurements and crown measurements made on a digitized-Zeiss-stereotope system (Fig. 3). A measurement procedure for the system has been described by Brun (1972). The tree and plot data were punched directly on cards for machine processing.

Tree diameters and volumes were estimated from the above tree variables using regression models of the following form:

$$
\mathrm{V} \text { or } \mathrm{D}=\mathrm{b}_{0}+\mathrm{b}_{1} \mathrm{H} \sqrt{\mathrm{CA}}+\mathrm{b}_{2} \sqrt{\mathrm{CA}}
$$

where $\mathrm{V}$ is total volume, $\mathrm{D}$ is diameter at breast height, $\mathrm{H}$ is photomeasured tree height, CA is crown area and $b_{0}, b_{1}$, and $b_{2}$ are regression coefficients which vary from species to species and depend on whether $\mathrm{V}$ or $\mathrm{D}$ is estimated. Stand volume and basal area estimates are compiled from the plot data and stock and stand tables can be prepared.

\section{Results}

Accuracy of the Inventory. Field data were collected to check the accuracy of the large-scale photo work. Eight fairly accessible field plots were checked for photo scale, species identification, tree height and diameter.

Hardwood and softwood species groups were correctly separated in nearly all cases; individual species were correctly identified with an accuracy of about $90 \%$. Most errors arose in discriminating white spruce and balsam fir.

Photo scale as determined from the radar altimeter was within $\pm 1 \%$ of the true scale $66 \%$ of the time. Tree height was measured with a bias of $-0.7 \mathrm{~m}$ and a standard deviation of $0.8 \mathrm{~m}$. This bias was attributed mainly to the radar altimeter and some loss of resolution in the images of tree tops as well as to the difficulty of locating the elevation of the forest floor beneath the thick forest canopies.

The gyro mount maintained the camera within $\pm 1 / 2$ degree of the vertical with a $90 \%$ probability. Tip and tilt of the aircraft was, therefore, considered not to have a significant effect on the accuracy of the plots measurements ${ }^{4}$.

The average volume per hectare for the inventory area was estimated with a standard error of $15 \%$. The accuracy of the inventory could be increased by increasing sample size and thus the cost.

The final results of this inventory using large-scale photography are shown in Table 2 (Bonnor 1974). 
Cost Analysis. The purpose of the cost analysis was to compare the effectiveness of the method with that of the conventional procedure based only on small-scale photography (for stratification) and ground survey. For the comparison, it was necessary to show only cost elements which were not common to both methods. Also, to complete the cost comparison, it was assumed that both methods would achieve the same level of accuracy in the estimates of volume or other statistics.

The cost elements, common to both methods and about the same magnitude, are listed in the upper section of Table 3 . Where additional costs occurred for one method or the other, the extra amount is shown separately in the lower half of the table. For example, in addition to the computation costs shared by both methods for calculating the required inventory statistics, computer costs associated only with the photo plot data are shown separately.

Costs, not common to both methods, are shown in the lower section of Table 3. The costs quoted were actual salaries of Forest Management Institute employees doing the work and the cost of outside services.

The equipment depreciation was placed at $\$ 2,000$ based on a purchase price of about $\$ 40,000$ for the airborne installation and $\$ 36,000$ for the photo-measurement equipment, a life of about ten years and the relatively small size of job. The depreciation figure, however, would vary greatly according to the choice of equipment, how much it is used, size of the job and the policy of the organization doing the work.

The aircraft cost was higher than usual for this type of job, having been increased considerably by a combination of equipment malfunction and bad weather. A larger inventory would also have greatly eased the impact of the high start-up cost and other fixed costs such as equipment installation, depreciation and overhead.

The costs which could be considered variable, depending on the number of plots measured, are shown in a separate column. The film and processing costs amounted to about $\$ 6.40$ per plot based on 63 measured photo plots. Sixty plots were required for the sampling design but 3 extras were measured for the time analysis. The costs of setting up a photo plot and measuring the trees including the computer processing was about $\$ 7.00$ per plot.

For comparison purposes, it was assumed that about 60 ground sample plots would be required to achieve the same accuracy as the method based on large-scale photos. This figure was arrived at analytically from an estimate of the population variance and the sampling design required to estimate volume. The cost of the ground sampling was assumed to be $\$ 100$ per plot, a commonly quoted figure, though the value varies greatly depending on the type and size of sampling plot, sampling design, access, topography, the kind of forest and other factors. Accordingly, the cost of the conventional inventory was crudely estimated at $\$ 6,000$ plus the costs common to both methods listed in Part A of Table 3 . In comparing the two methods then, the total costs were about the same. As explained later, the large scale photo method would gain in relative effectiveness as the size of the inventory or the intensity of the sampling was increased.

Operational Problems. A major problem which arose during the trial of the method was a long delay caused by a malfunctioning radar altimeter and subsequent grounding of the aircraft due to bad weather. Two weeks of standby charges nearly doubled the cost of the inventory. Aside from setting up better aircraft rental arrangements to hold down such costs, the delay demonstrated the importance of bench testing equipment before installation, carrying out test flights before the main mission, and developing the film immediately upon completion of a flight to ensure that the film has been properly exposed and all photogrammetric data have been clearly recorded.

Another problem was the difficulty of locating the photo plots on the ground. It was found that the plots could be more readily located if parallel flight lines were flown and if a short burst of photographs was 
taken over readily identified ground features on the flight line. This trial showed the value of an experienced air survey pilot as all lines were parallel and directly over the desired locations which were defined by the sampling design. Also the twinengine aircraft used provided more space and better stability than a smaller aircraft.

During the photo-measurement work, some difficulties arose in differentiating balsam fir and white spruce. However, a few field checks enabled the photo interpreter to make a $90 \%$ or better correct identification of individual species. It was also found from similar photography in the fall, that changes in phenology could further assist in the separation of spruce and balsam fir. Nevertheless, the above difficulty demonstrated the need for some field work to monitor such problems and to apply appropriate corrections when necessary.

Similarly, spot checks were required to monitor variations in the performance of the radar altimeter, the measurement work and the regression equations. Checks on the accuracy of tree-height measurements were particularly useful in detecting and correcting biases due to the altimeter and variations in operator performance.

The tree heights were determined from parallax measurements made on the stereotope system (Fig. 3). The work was carried out both faster and more accurately when, rather than taking parallax readings at both the top and base of every tree, the base readings were obtained from a groundsurface reference derived from a few parallax readings made through breaks in the forest canopy. The measurement work was reduced to these few readings and the parallax readings on the tree tops. A computer program was used to derive the ground reference and was used to calculate the tree heights from the parallax readings. Reduction of measurement time by such means is critical to the success of the method.

\section{Conclusions and recommendations}

Valuable experience has been gained in testing the large-scale photo method under operational conditions. Problems were encountered and solutions sought in efforts to establish the usefulness of the method in forest inventory. Accuracy was considered satisfactory for the inventory requirements posed; major cost elements were identified.
The malfunction of equipment and the subsequent delay in the flight due to bad weather tied up an aircraft and greatly increased inventory cost.

Based on this experience, an important recommendation is that equipment should be thoroughly tested before and after installation and that a short local flight should be carried out to ensure that the entire system is functioning properly. Other recommendations are

(1) process the film of a sample strip immemediately after the photo mission to ensure the correct film exposure and proper functioning of all equipment;

(2) acquire photography when the deciduous trees are leafless but when there is little or no snow on the ground; better species identification can be made with fall photography but spring has the added advantage of preceding a full summer for field work;

(3) carry out a small amount of ground work to check and, if necessary, correct for sources of systematic error and to determine or check the regression equation coefficients;

(4) use an experienced survey pilot to ensure that the flight lines are straight and parallel and that the aircraft is as stable as possible during the photography;

(5) carry out further trials over a much larger area, preferably where inventory data are available, for a better assessment of cost and accuracy. The method is designed for inventories of large, remotely located areas and should be tested under such conditions for a more realistic evaluation.

Many problems associated with implementing the large-scale photo method for forest inventories have been isolated and solved as a result of previous research and tests. Several additional operational problems were encountered on the present forest inventory trial and adjustments have been made to minimize these problems in future trials. In general, procedures for taking and using large-scale photography have been worked out and a method demonstrated as a viable alternative to inventories based only on ground data. The success of this method depends on its use in extensive inventories of remote areas or other areas where access is difficult and expensive. A full-scale application is required to establish the degree to which the largescale photo method can replace ground surveys and reduce the cost of larger forest inventories. 